\section{Prevalence, determinants, and effects of violence during pregnancy: A maternity-based cross-sectional study in Luanda, Angola}

\author{
Tazi Nimi,, ${ }^{1,2}$ Sílvia Fraga,,3 \\ Diogo Costa, ${ }^{2}$ Paulo Campos, ${ }^{1}$ \\ Henrique Barros ${ }^{2,3}$
}

${ }^{1}$ Faculty of Medicine of the University

Agostinho Neto, Luanda, Angola;

${ }^{2}$ EPIUnit - Instituto de Saúde Pública da

Universidade do Porto, Porto, Portugal;

${ }^{3}$ Department of Public Health, Forensic

Sciences and Medical Education,

University of Porto Medical School,

Porto, Portugal

\begin{abstract}
Information on the extent of violence against women is scarce in Angola. This study aims to estimate the prevalence of violence against pregnant women in Angola and to identify its sociodemographic determinants and effects on pregnancy outcomes. A cross-sectional study was conducted between December 2012 and February 2013, involving 995 women who delivered at a Maternity in Luanda, Angola. Information was collected through questionnaires administered by interviewers. The prevalence of violence during pregnancy was $13.0 \%$. Exclusively physical, psychological or sexual violence was reported by $4.3 \%, 7.7 \%$ and $0.2 \%$ of the women, respectively. After adjustment, the occurrence of physical violence decreased with increasing age and education, and was more common among women who consumed alcohol during pregnancy, while psychological violence was significantly more frequent among women aged 20 to 24 years and those who had their first sexual intercourse before the age of 15 , and less frequent among those who were married or in cohabitation. This first study describing violence against pregnant Angolan women showed that violence is a frequent event, supporting that violence assessment should be considered in antenatal care.
\end{abstract}

\section{Introduction}

Violence against women is a serious human rights violation, a significant threat to women's health and wellbeing, and a major social and public health problem. It has been observed in every social, cultural, economic, and religious groups, ${ }^{1}$ and it is defined as a pattern of intentional, coercive, and violent behavior directed at women. However, when violence occurs during pregnancy, its impact can be of more concern due to potential negative consequences to both the mother and her unborn child. ${ }^{2,3}$

Internationally, reported rates of intimate partner violence (IPV) involving pregnant women ranged between $0.9 \%$ and $44 \%$, but few studies were conducted in low and middle-income countries. ${ }^{3-6}$ A metaanalysis of 13 studies describing IPV during pregnancy in African populations, during the first decade of 2000 , found an overall prevalence of $15.2 \%$ with individual estimates ranging from $2 \%$ to $57 \%$, thus yielding some of the highest rates reported globally. ${ }^{5}$ Few studies have been conducted in the African context to identify determinants and risk factors of IPV. ${ }^{5,7,8}$ However, a systematic review of African studies on IPV against pregnant women found as major risk factors the alcohol consumption by partner (or self) and drug use, sexual risktaking, HIV infection and a history of violence. ${ }^{5}$ Also, another study conducted in Uganda found that high education of women and marriage satisfaction were associated with a lower risk of intimate partner violence, while the husband having another partner were associated with a higher risk of intimate partner violence. ${ }^{9}$

Violence against pregnant women has profound physical, psychological, and societal implications, including serious injury and death of the victim. Women abused during pregnancy are three times more likely to become an attempted or completed femicide victim than their non-pregnant abused counterparts. ${ }^{10}$ There are important adverse maternal health outcomes associated with violence against pregnant women, and this form of violence is also of particular concern because of the additional risk to the unborn child. Violence can harm the fetus through direct injury, causing placental damage, premature contractions, membrane rupture, or fetal death, or through indirect mechanisms such as stress or violence-related maternal health problems. ${ }^{5,11,12}$ As violence was shown to increase the frequency of preterm birth or low birthweight, it might additionally influence child prognosis considering the known developmental origins of health and disease. ${ }^{13}$

In African countries, domestic violence is often not perceived as a legal issue and therefore, it is not frequently reported to law enforcement. A survey involving almost nine thousand women, aged 15-49 years and currently married or in union, living in six major Nigerian cities, showed that
Correspondence: Henrique Barros, EPIUnit Instituto de Saúde Pública da Universidade do Porto, Rua das Taipas 135, 4050-600 Porto, Portugal.

Tel.: +351222061820 .

E-mail: hbarros@med.up.pt

Key words: abuse; pregnancy; Angola.

Acknowledgements: The authors acknowledge the support of Calouste Gulbenkian Foundation, the Board of Directors of Lucrécia Paím Maternity and the National Malaria Program.TM acknowledges the National Institute of Management Scholarships (INAGBE) and the Faculty of Medicine of the University Agostinho Neto. SF acknowledge the Portuguese Foundation for Science and Technology contract (CEECIND/01516/2017). The EPIUnit, Institute of Public Health, University of Porto, Portugal (UID/DTP/04750/2013) is funded by the Portuguese Foundation for Science and Technology.

Contributions: TM, references search, data collecting and manuscript writing; SF data analyzing and manuscript writing; DC, PC, manuscript reviewing; HB, conceptualizing the study, manuscript writing and reviewing. All the authors approved the final version of the manuscript.

Conflict of interest: the authors declare no potential conflict of interests

Funding: none.

Received for publication: 14 February 2019. Revision received: 12 August 2019.

Accepted for publication: 17 August 2019.

This work is licensed under a Creative Commons Attribution NonCommercial 4.0 License (CC BY-NC 4.0).

${ }^{(}{ }_{C}$ Copyright: the Author(s), 2019

Licensee PAGEPress, Italy

Journal of Public Health in Africa 2019; 10:1050 doi:10.4081/jphia.2019.1050

$26.7 \%$ considered that a man is justified in beating his wife if he suspects her of being unfaithful, a proportion that reached $57.3 \%$ in southern cities, and $11.7 \%$ said that beating was justified if she refuses to have sex with him. ${ }^{14}$ This context can change the way pregnant women experience risk and prevention compared to elsewhere. Also, violence is mainly regarded as physical aggression and psychological violence less valued. However, emotional IPV during pregnancy negatively affects women's mental health in the postnatal period, as shown in Harare, Zimbabwe, and clinicians and 
researchers should consider it when addressing violence and health. ${ }^{15}$

In Angola, information on the extent of gender violence is scarce, but recent regulation was issued to combat domestic violence, responding to the increased social recognition of the problem and making it a new surveillance challenge. In this study, using a sample of women delivered in the largest maternity of Luanda, Angola, we aimed to determine the prevalence of violence against women during pregnancy, its social determinants and effects on the pregnancy outcomes.

\section{Materials and Methods \\ Setting}

A cross-sectional study was conducted in Luanda, among women delivered at the largest public maternity of Angola. Maternity Lucrécia Paím is a national reference for maternal health care, training of health professionals and research. As a tertiary health care facility, it receives cases referred from facilities in lower levels of care, it performs caesarean and vaginal deliveries, provides intensive care to women and newborns, has specialized areas for eventful pregnancies and immediate puerperal complications and has on site laboratory support. During recruitment of participants, from December 2012 to February 2013, 5442 deliveries were recorded in the Maternity, 1686 were cesarean sections and 3534 vaginal births while 215 stillbirths were identified.

\section{Participants}

Women were invited to participate in the study after delivery and interviewed during the hospital stay. Women with twin pregnancies, foreign nationality, residing in the Province of Luanda for less than six months or presenting severe clinical conditions, such as eclampsia, complicated malaria or post-partum hemorrhage, were not considered for invitation. Women having a vaginal delivery are usually discharged after 6 hours while women undergoing caesarean remained in the hospital 3 to 7 days. Women were approached during daytime (from 8 a.m. to 5 p.m.) and to maximize recruitment, balance cases and manage resources, and women were visited on specific days of the week - Mondays, Wednesdays and Fridays for vaginal deliveries and Tuesdays and Thursdays for caesarean. Women were given insecticide impregnated bed nets after completing the questionnaire.

During the recruitment period, 1040 women were invited to participate, and 40 refused (96\% response rate). These women were similar to participants regarding demographic, socioeconomic and clinical characteristics, but they all had vaginal births and the main reason stated for not participating was pain after delivery. For study analysis, we excluded 5 participants with missing information on all key variables in their clinical files, resulting in a final sample of 995 women.

To measure the prevalence of violence, a sample size of 400 was estimated considering a $95 \%$ confidence level, a prevalence of violence in pregnancy of $15 \%,{ }^{5}$ and a $5 \%$ margin of error. However, a sample size of 1000 was calculated, using the same parameters and a power of $80 \%$, to guarantee the needed statistical power to assess the association of low socioeconomic status (based on educational level) with violence during pregnancy, assuming that women with low socioeconomic status have twice the odds of reporting an experience of abuse when compared with those from high socioeconomic status. ${ }^{16}$

\section{Data collection}

Data were collected by face to face interviews using a structured questionnaire administered by six trained interviewers in a reserved area and without the presence of the husband or partner. Written informed consent was obtained from all participants.

The questionnaire collected information on demographic and socioeconomic characteristics, past clinical history, use of prenatal care, smoking and alcohol consumption, and events of present pregnancy, by using specific standardized questions based on previous studies focusing on maternal and infant health, ${ }^{17}$ ensuring comparability of the selected questions and answering categories.

Clinical variables related to hospital admission, vital signs at admission, delivery and newborn were obtained from the clinical charts.

The project was approved by the Ethics Committee of the Faculty of Medicine of the University Agostinho Neto, Luanda. The study followed the World Health Organization ethical and safety guidelines for the conduct of research on gender violence. $^{18}$

\section{Violence during pregnancy}

Violence during the current pregnancy was ascertained with a set of questions as used in the Abuse Assessment Screen questionnaire ${ }^{19}$ plus the question "During pregnancy, have you ever been repressed or humiliated, hurt, spoken aggressively?". This allowed us to approach psychological violence, besides physical and sexual vio- lence. Respondents who answered "Yes" to at least one of the listed questions were considered to have experienced violence. Those who had experienced violence were then asked about the relation to the aggressor (partner, family member, neighbor or other) and the trimester of pregnancy when the last violent act occurred.

\section{Covariates}

For this study we considered the following maternal demographic and socioeconomic characteristics: age (categorized in 13-19, 20-24, 25-29, $\geq 30$ years old), educational level (categorized in four groups: 0-4, $5-8,9-12, \geq 13$ years of formal education), marital status (married or in cohabitation, and single), place of residence (urban if living in Luanda, periurban if in other municipalities in Province of Luanda, specifically Viana, Cazenga, Belas, Cacuaco, Icolo E Bengo and Kissama), household source of electricity ( the options were no electricity, public or alternative source), water source (the options were piped water, fountain or tank), monthly family income $(<100,100$ $300,>300$ dollars, do not know/do not say). Smoking during pregnancy was recorded as "yes or no", regardless of the number of cigarettes and period of pregnancy, and alcohol consumption according to the question "Have you taken any alcoholic beverage during this pregnancy?

The characteristics considered to describe reproductive related health were age at first intercourse $(<15$ years old or $\geq 15$ ), use of oral contraception (yes or no), history of previous pregnancies (yes or no), timing of first antenatal care visit ( $1^{\text {st }}$ trimester, $2^{\text {nd }}$ trimester, $3^{\text {rd }}$ trimester), number of antenatal care visits (stratified in $<4$ and $\geq 4$ ) and HIV diagnosis (yes or no) were also self-reported by the women. The pregnancy was classified as high risk when women indicated the occurrence in the current or previous pregnancies of any of the following: threat of abortion, hemorrhage, hypertension, diabetes, malaria, twin pregnancies, previous caesarean section or age 35 years or older.

The adverse pregnancy outcomes considered were preterm (gestational age at birth $<37$ weeks, according to the date of the last menstrual period), low birthweight $(<2500 \mathrm{~g})$ and fetal status (livebirth or stillbirth).

\section{Statistical Analysis}

Prevalence of violence was expressed as the percentage of women who reported at least one form of violence during pregnancy, and also computed according to the specific type of violence: physical, psychological or sexual. The $95 \%$ Confidence 
Intervals (CI) for the point estimates were calculated.

Chi-square test was used to compare the prevalence of physical and of psychological violence according to demographic, socioeconomic, lifestyle, reproductive healthrelated characteristics and the pregnancy outcomes. For regression analysis, we combined physical violence with sexual violence. Odds ratios (OR) and respective 95\% confidence intervals (CI) were computed by using Logistic Regression to assess the association of these specific factors with psychological and physical violence victimization. The criteria to include variables in the logistic models were based on statistical criteria but also on the previous theoretical literature. Thus, significant results $(p<0.05)$ observed in the univariate analysis (as age, alcohol consumption, age of first sexual intercourse and history of previous pregnancy) but also socioeconomic factors were included in the final models. Variables in the final model were tested for multicollinearity and the Hosmer and Lemeshow test ( $p<0.05$ represents poor fit) and Pseudo $\mathrm{R}^{2}$ were used to assess the goodness of fit for logistic regression models.

The analysis was performed using SPSS $^{\circledR} 21$.

\section{Results}

As shown in Table 1, $129(13.0 \%$, 95\%CI: 11 to $15 \%$ ) women reported being victims of any type of violence during pregnancy. The prevalence of physical violenceonly was $4.3 \%$ (95\% CI: 3.1 to $5.6 \%$ ), psychological violence-only was $7.7 \%$ (95\%CI: 6.1 to $9.2 \%$ ) and sexual violenceonly $0.2 \%$ (95\%CI: 0 to $0.5 \%)$. Considering all the women that reported to be victims of violence $(n=129)$, seven women reported to be victims of more than one type of violence during pregnancy, seventy women $(54.3 \%)$ identified the partner as the aggressor and $55(42.6 \%)$ described the most recent episode of violence during the third trimester of pregnancy. However, 11 women reported violence during all period of pregnancy.

Table 2 shows that women experiencing physical violence during the index pregnancy were significantly younger $(<20$ years old: $34.6 \% v s$ 18.5\%), more often consumed alcohol (40.4\% vs 17.0\%), had their first sexual intercourse before the age of 15 years $(20.8 \%$ vs $9.6 \%)$ compared to women not experiencing violence. Victims of psychological violence were less frequently found among adolescents, being mainly young adults, more often lived in households without electricity (5.3\% vs $1.3 \%)$.
Victims of psychological violence more frequently had their first antenatal care visit during the 3rd trimester of pregnancy $(9.7 \%$ vs $3.0 \%$ ). Also, women experiencing physical violence during the index pregnancy had a high risk pregnancy (36.5\% vs $21.2 \%)$ and more frequently delivered a low birthweight baby $(24.0 \%$ vs $13.9 \%$; OR=1.95, 95\%CI: 0.99 to 3.84 ) compared to women not experiencing violence. Although there were many missing data regarding gestational age, women who experienced physical violence were also more frequently delivered of a preterm newborn $(36.4 \%$ vs $25.6 \%$; $\mathrm{OR}=1.66,95 \% \mathrm{CI}: 0.80$ to 3.46 ). When only live births were considered the point estimates were similar although there was an attenuation of the risk for low birthweight $(\mathrm{OR}=1.70,95 \% \mathrm{CI}: 0.79$ to 3.63$)$ and a small increase for preterm birth $(\mathrm{OR}=1.77$, 95\% CI: 0.83 to 3.79 ).

After adjustment for maternal age, education, marital status, place of residence, monthly family income, alcohol consumption, age of the first sexual intercourse, and previous pregnancy, it was observed a significant independent association of physical violence with maternal age, education and alcohol consumption. Considering the determinants of psychological abuse, after adjustment a significantly higher risk was observed among women aged 20 to 24 years and those who had the first sexual intercourse before the age of 15 , while being married or living in cohabitation significantly decreased the risk of psychological violence (Table 3 ).

\section{Discussion and Conclusions}

In this study, to the best of our knowledge the first conducted in Angola on interpersonal violence during pregnancy, one in every 8 women experienced violence dur- ing this period of life, and in half cases, the partner was the aggressor.

The prevalence of physical violence in our study was $4 \%$, similar to other African countries. A previous large review showed a prevalence of physical violence against pregnant women ranging between $3.8 \%$ and $13.5 \%$ among 8 African countries included. 20 The 2013 Nigeria Demographic and Health Survey also reported that $5 \%$ of women had experienced physical violence during pregnancy compared to an overall prevalence of $30 \%$ among all women of reproductive age. ${ }^{21}$ We found a prevalence of $8 \%$ of psychological violence during pregnancy. Even though it might be low when comparing to other African settings (varied from $25 \%$ in Uganda to $49 \%$ in South Africa), ${ }^{5}$ psychological violence can be viewed as a normative behavior by women. ${ }^{22}$

In Africa, $16 \%$ to $59 \%$ of women report having been sexually assaulted during their lifetime, often during childhood. ${ }^{8}$ A review of 7231 studies that provided 412 estimates for 56 countries, ${ }^{23}$ showed that $7.2 \%$ of women ever experienced non-partner sexual violence in 2010, and the highest estimates were in sub-Saharan Africa, central $(21 \%)$ and southern (17.4\%). Considering these findings, our rate of sexual violence is unexpectedly low. For various reasons, including the stigma and blame attached to sexual violence, this value is likely to be an underestimate, and one can expect that victims differentially avoided or had no conditions to search for delivery in a health facility. It was previously shown in different societies that the partner is the most frequent perpetrator both when globally considering violence against women or just focusing on violence during pregnancy. ${ }^{9,24,25}$ Also, in this study conducted in Angola, the partner was most often identified as the perpetrator, but in approximately

Table 1. Distribution of women according to perpetrator and timing of violence during Pregnancy.

$\begin{array}{cccc}\begin{array}{c}\text { Physical* Psychological* } \\ (n=43)\end{array} & \begin{array}{c}\text { Sexual* } \\ (n=77)\end{array} & \begin{array}{c}\text { Combined forms** } \\ (n=2)\end{array} & \text { Any form } \\ (n=7) & (n=129)\end{array}$

\begin{tabular}{lccccc} 
Perpetrator & & & & & \\
Partner & 17 & 46 & 2 & 5 & 70 \\
Family member & 11 & 13 & 0 & 2 & 26 \\
Neighbor & 8 & 15 & 0 & 0 & 23 \\
Other & 4 & 3 & 0 & 0 & 7 \\
No information & 3 & 0 & 0 & 0 & 3 \\
Trimester of Pregnancy*** & 4 & 15 & 0 & 3 & \\
$1^{\text {st }}$ & 20 & 18 & 0 & 1 & 39 \\
$2^{\text {nd }}$ & 15 & 35 & 2 & 3 & 55 \\
$3^{\text {rd }}$ & 4 & 9 & 0 & 0 & 13 \\
No information & 4 & & & \\
\hline
\end{tabular}

${ }^{*}$ Number (\%) of women experiencing a single type of violence. ${ }^{* *}$ When more than one form of violence was reported. ${ }^{* * *}$ Trimester of violence episode or when the most recent episode of violence occurred if violence spanned over different trimesters. 
Table 2. Characteristics of participants and its distribution according to the presence of physical or psychological violence.

\begin{tabular}{|c|c|c|c|c|c|}
\hline & № & 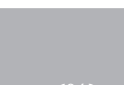 & $\begin{array}{l}\text { lence d } \\
\text { al* }\end{array}$ & Psyc & $\mathrm{al}^{* *}$ \\
\hline & n (\%) & n (\%) & p & n (\%) & p \\
\hline $\begin{array}{l}\text { Maternal age (years) } \\
13-19 \\
20-24 \\
25-29 \\
\geq 30\end{array}$ & $\begin{array}{l}160(18.5) \\
201(23.3) \\
213(24.7) \\
290(33.6)\end{array}$ & $\begin{array}{l}18(34.6) \\
16(30.8) \\
10(19.2) \\
8(15.4)\end{array}$ & 0.004 & $\begin{array}{l}9(11.7) \\
26(33.8) \\
16(20.8) \\
26(33.8)\end{array}$ & 0.138 \\
\hline $\begin{array}{l}\text { Education (years) } \\
0-4 \\
5-8 \\
9-12 \\
\geq 13 \\
\end{array}$ & $\begin{array}{c}123(14.3) \\
313(36.4) \\
330(38.4) \\
93(10.8)\end{array}$ & $\begin{array}{c}13(25.5) \\
19(37.3) \\
17(33.3) \\
2(3.9)\end{array}$ & 0.088 & $\begin{array}{l}14(18.2) \\
22(28.6) \\
34(44.2) \\
7(9.1)\end{array}$ & 0.433 \\
\hline $\begin{array}{l}\text { Marital status } \\
\text { Married (or in cohabitation) } \\
\text { Single }\end{array}$ & $\begin{array}{l}672(77.6) \\
194(22.4)\end{array}$ & $\begin{array}{l}37(71.2) \\
15(28.8)\end{array}$ & 0.365 & $\begin{array}{l}55(71.4) \\
22(28.6)\end{array}$ & 0.274 \\
\hline $\begin{array}{l}\text { Place of Residence } \\
\text { Urban } \\
\text { Periurban }\end{array}$ & $\begin{array}{l}446(51.9) \\
413(48.1)\end{array}$ & $\begin{array}{l}23(44.2) \\
29(55.8)\end{array}$ & 0.350 & $\begin{array}{l}37(48.7) \\
39(51.3)\end{array}$ & 0.673 \\
\hline $\begin{array}{l}\text { Household electricity } \\
\text { No } \\
\text { Public } \\
\text { Alternative source }\end{array}$ & $\begin{array}{c}11(1.3) \\
700(80.9) \\
154(17.8)\end{array}$ & $\begin{array}{c}1(1.9) \\
38(73.1) \\
13(25.0)\end{array}$ & 0.381 & $\begin{array}{c}4(5.3) \\
59(77.6) \\
13(17.1)\end{array}$ & 0.029 \\
\hline $\begin{array}{l}\text { Water } \\
\text { Piped water } \\
\text { Fountain } \\
\text { Tank }\end{array}$ & $\begin{array}{l}353(40.8) \\
345(39.8) \\
168(19.4)\end{array}$ & $\begin{array}{c}19(36.0) \\
24(46.0) \\
9(17.3)\end{array}$ & 0.666 & $\begin{array}{l}33(42.9) \\
29(37.7) \\
15(19.5)\end{array}$ & 0.923 \\
\hline $\begin{array}{l}\text { Monthly Family Income (US\$) } \\
\leq 300 \\
>300 \\
\text { Do not know/do not say }\end{array}$ & $\begin{array}{l}321(38.0) \\
217(25.7) \\
306(36.3)\end{array}$ & $\begin{array}{l}18(37.5) \\
12(25.0) \\
18(37.5)\end{array}$ & 0.984 & $\begin{array}{l}32(42.1) \\
25(32.9) \\
19(25.0)\end{array}$ & 0.124 \\
\hline $\begin{array}{l}\text { Alcohol consumption } \\
\text { No } \\
\text { Yes }\end{array}$ & $\begin{array}{l}719(83.0) \\
147(17.0)\end{array}$ & $\begin{array}{l}31(59.6) \\
21(40.4)\end{array}$ & $<0.001$ & $\begin{array}{l}59(76.6) \\
18(23.4)\end{array}$ & 0.160 \\
\hline $\begin{array}{l}\text { 1st sexual intercourse (years) } \\
\quad<15 \\
\quad \geq 15\end{array}$ & $\begin{array}{c}77(9.6) \\
729(90.4)\end{array}$ & $\begin{array}{l}10(20.8) \\
38(79.2)\end{array}$ & 0.024 & $\begin{array}{l}12(16.2) \\
62(83.8)\end{array}$ & 0.069 \\
\hline $\begin{array}{l}\text { Ever used oral contraception } \\
\text { No } \\
\text { Yes }\end{array}$ & $\begin{array}{l}520(60.0) \\
346(40.0)\end{array}$ & $\begin{array}{l}34(65.4) \\
18(34.6)\end{array}$ & 0.536 & $\begin{array}{l}49(63.6) \\
28(36.4)\end{array}$ & 0.620 \\
\hline $\begin{array}{l}\text { Previous pregnancies } \\
\text { No } \\
\text { Yes }\end{array}$ & $\begin{array}{l}239(27.6) \\
627(72.4)\end{array}$ & $\begin{array}{l}22(42.3) \\
30(57.7)\end{array}$ & 0.034 & $\begin{array}{l}20(26.0) \\
57(74.0)\end{array}$ & 0.863 \\
\hline $\begin{array}{l}\text { First antenatal care visit } \\
1^{\text {st }} \text { trimester } \\
2^{\text {nd }} \text { trimester } \\
3^{\text {rd }} \text { trimester }\end{array}$ & $\begin{array}{c}436(52.3) \\
373(44.7) \\
25(3.0)\end{array}$ & $\begin{array}{c}25(55.6) \\
16(35.6) \\
4(8.9)\end{array}$ & 0.068 & $\begin{array}{c}37(51.4) \\
28(38.9) \\
7(9.7)\end{array}$ & 0.011 \\
\hline $\begin{array}{l}\text { Frequency antenatal care visit } \\
\quad<4 \\
\geq 4 \\
\text { Yes }\end{array}$ & $\begin{array}{l}520(63.6) \\
298(36.4) \\
184(21.2)\end{array}$ & $\begin{array}{l}25(58.1) \\
18(41.9) \\
19(36.5)\end{array}$ & $\begin{array}{l}0.577 \\
0.016\end{array}$ & $\begin{array}{l}44(61.1) \\
28(38.9) \\
20(26.0)\end{array}$ & $\begin{array}{l}0.774 \\
0.412\end{array}$ \\
\hline $\begin{array}{l}\text { Cesarean delivery } \\
\text { No } \\
\text { Yes }\end{array}$ & $\begin{array}{l}494(57.0) \\
372(43.0)\end{array}$ & $\begin{array}{l}27(51.9) \\
25(48.1)\end{array}$ & 0.562 & $\begin{array}{l}39(50.6) \\
38(49.4)\end{array}$ & 0.335 \\
\hline $\begin{array}{l}\text { HIV infection } \\
\text { No } \\
\text { Yes }\end{array}$ & $\begin{array}{c}860(99.3) \\
6(0.7)\end{array}$ & $\begin{array}{c}50(96.2) \\
2(3.8)\end{array}$ & 0.108 & $\begin{array}{c}74(96.1) \\
3(3.9)\end{array}$ & 0.031 \\
\hline $\begin{array}{l}\text { Preterm newborn } \\
\text { No } \\
\text { Yes }\end{array}$ & $\begin{array}{l}439(74.4) \\
151(25.6)\end{array}$ & $\begin{array}{l}21(63.6) \\
12(36.4)\end{array}$ & 0.243 & $\begin{array}{l}40(75.5) \\
13(24.5)\end{array}$ & 0.995 \\
\hline $\begin{array}{l}\text { Birthweight } \\
<2500 \mathrm{~g} \\
\geq 2500 \mathrm{~g}\end{array}$ & $\begin{array}{l}116(13.9) \\
716(86.1)\end{array}$ & $\begin{array}{l}12(24.0) \\
38(76.0)\end{array}$ & 0.050 & $\begin{array}{l}10(13.3) \\
65(86.7)\end{array}$ & 0.884 \\
\hline $\begin{array}{l}\text { Fetal status } \\
\text { Livebirth } \\
\text { Stillbirth }\end{array}$ & $\begin{array}{c}790(91.2) \\
76(8.8)\end{array}$ & $\begin{array}{c}47(90.4) \\
5(9.6)\end{array}$ & 0.836 & $\begin{array}{c}72(93.5) \\
5(6.5)\end{array}$ & 0.636 \\
\hline
\end{tabular}

*Physical violence includes women reporting physical abuse-only or any combination of physical, sexual and psychological abuse; **Psychological violence includes women reporting only psychological abuse. 
half of the cases, family members or neighbors were implicated. In many African societies, the neighbor is considered as a close family member; hence it was not surprising to find the neighbor amongst the most commonly reported aggressors as found, except for Ethiopia and Japan, in the WHO study countries. ${ }^{23}$

In our study, younger age and alcohol consumption were significantly associated with physical violence. These results are in line with studies showing that the risk of violence decreases with age, ${ }^{7}$ and that alcohol consumption is risk factors for violence. ${ }^{24}$ Alcohol use during pregnancy is a leading cause of stillbirth, spontaneous abortion, preterm delivery, and various child neurobehavioral problems potentially interacting with abuse in the occurrence of adverse fetal outcomes. Addiction is easier to diagnose. Help and treatment for cessation should be provided, but domestic violence should be looked for. ${ }^{26}$

Early initiation of sexual activity was a risk factor both for physical and psychological violence. Younger pregnant women tend to engage early in a marital relationship, and are the most emotionally and financially dependent on their partners, making them vulnerable to abuse.

HIV-positive women experienced violence during pregnancy significantly more often than HIV-negative women. As we can see in Table 2, considering any violence, 5 out of 11 were victims compared to 124 out of the 984 HIV-negative women $(p=0.006)$, and there was a significant association between HIV infection and psychological violence. Also, five previous studies presented adjusted significant associations between HIV and IPV during pregnancy, the $95 \%$ estimate for the summary OR ranging from 1.48 to $3.10,5$ and it was reported that violence increases when the woman is known to be HIV positive. ${ }^{27}$

The links between domestic violence and sexually transmitted diseases, unwanted pregnancy, contraception and abortion, maternal morbidity and mortality, and adverse pregnancy outcomes are increasingly recognized. ${ }^{28}$ We also found that exposure to physical violence during preg- nancy was associated with an increased risk of low birthweight. Our results are consistent with an Australian cohort study, ${ }^{29}$ that found an adjusted risk of $2.04(95 \% \mathrm{CI}=$ 1.50 to 2.77 ) for adverse fetal complications, including low birth weight in indigenous women hospitalized for interpersonal violence and with a recent review of studies on intimate partner violence during pregnancy and risk of adverse infant outcomes which found an increased risk of low birthweight and preterm, of around 2, but a large heterogeneity. ${ }^{30}$ The pathway from violence to low birth weight is not clear, with possible direct traumatic effects or a stress-related increase in maternal chronic health conditions inducing preterm labour. ${ }^{31}$ We could not value duration of pregnancy, as there was a high proportion of women to whom it was not possible to calculate gestational age and consequently to evaluate any impact on the prevalence of small for gestational age babies.

A recognized limitation of this study is the fact that it was facility-based; therefore, the effect of selection bias limits the gener-

Table 3. Determinants of physical or psychological violence: crude and logistic regression adjusted estimates of odds ratios (OR) and respective $95 \%$ Confidence intervals (95\% CI).

\begin{tabular}{|c|c|c|c|c|}
\hline & \multicolumn{4}{|c|}{ Violence during pregnancy } \\
\hline & \multicolumn{2}{|c|}{ Physical* OR (95\%CI) } & \multicolumn{2}{|c|}{ Psychological** OR (95\%CI) } \\
\hline & Crude & Adjusted ${ }^{1}$ & Crude & Adjusted $^{1}$ \\
\hline \multicolumn{5}{|l|}{ Maternal age (years) } \\
\hline $13-19$ & 1 & 1 & 1 & 1 \\
\hline $20-24$ & $0.71(0.35,1,43)$ & $0.77(0.30,2.00)$ & $2.30(1.05,5.05)$ & $2.55(1.03,6.35)$ \\
\hline $25-29$ & $0.42(0.19,0.93)$ & $0.36(0.11,1.14)$ & $1.33(0.57,3.10)$ & $1.56(0.54,4.47)$ \\
\hline$\geq 30$ & $0.24(0.10,0.58)$ & $0.21(0.06,0.73)$ & $1.59(0.73,3.48)$ & $2.06(0.74,5.76)$ \\
\hline \multicolumn{5}{|l|}{ Education (years) } \\
\hline $0-4$ & 1 & 1 & 1 & 1 \\
\hline $5-8$ & $0.57(0.27,1.20)$ & $0.47(0.20,1.13)$ & $0.62(0.31,1.25)$ & $0.71(0.33,1.54)$ \\
\hline $9-12$ & $0.49(0.23,1.03)$ & $0.38(0.15,0.99)$ & $0.90(0.47,1.74)$ & $1.03(0.48,2.20)$ \\
\hline$\geq 13$ & $0.20(0.04,0.92)$ & $0.27(0.05,1.40)$ & $0.66(0.26,1.70)$ & $0.68(0.24,1.92)$ \\
\hline \multicolumn{5}{|l|}{ Marital status } \\
\hline Married (or in cohabitation) & $0.71(0.38,1.32)$ & $1.21(0.51,2.85)$ & $0.72(0.43,1.21)$ & $0.46(0.23,0.90)$ \\
\hline Single & 1 & 1 & 1 & 1 \\
\hline \multicolumn{5}{|l|}{ Place of Residence } \\
\hline Urban & $0.73(0.42,1.29)$ & $0.69(0.35,1.34)$ & $0.88(0.55,1.40)$ & $0.78(0.47,1.29)$ \\
\hline Periurban & 1 & 1 & 1 & 1 \\
\hline \multicolumn{5}{|l|}{ Monthly Family Income (US\$) } \\
\hline$\leq 300$ & 1 & 1 & 1 & 1 \\
\hline$>300$ & $0.99(0.47,2.09)$ & $0.83(0.36,1.91)$ & $1.16(0.67,2.01)$ & $1.10(0.62,1.96)$ \\
\hline Do not know/do not say & $1.05(0.54,2.05)$ & $0.67(0.29,1.49)$ & $0.62(0.35,1.12)$ & $0.53(0.27,1.02)$ \\
\hline \multicolumn{5}{|l|}{ Alcohol consumption } \\
\hline No & 1 & 1 & 1 & 1 \\
\hline Yes & $3.31(1.85,5.93)$ & $3.25(1.16,6.55)$ & $1.49(0.85,2.60)$ & $1.52(0.85,2.73)$ \\
\hline \multicolumn{5}{|l|}{$1^{\text {st }}$ sexual intercourse (years) } \\
\hline$<15$ & $2.49(1.20,5.20)$ & $1.39(0.59,3.30)$ & $1.83(0.95,3.55)$ & $2.39(1.16,4.92)$ \\
\hline$\geq 15$ & 1 & 1 & 1 & 1 \\
\hline \multicolumn{5}{|l|}{ Previous pregnancies } \\
\hline No & 1 & 1 & 1 & 1 \\
\hline Yes & $0.52(0.29,0.92)$ & $0.74(0.30,1.81)$ & $1.09(0.64,1.85)$ & $1.15(0.56,2.39)$ \\
\hline Pseudo $R^{2}$ & & $11 \%$ & & $6 \%$ \\
\hline Hosmer and Lemeshow test & & $\mathrm{p}=0.218$ & & $\mathrm{p}=0.166$ \\
\hline
\end{tabular}

*Physical violence includes women reporting physical abuse-only or any combination of physical, sexual and psychological abuse; **Psychological violence includes women reporting only psychological abuse.

${ }^{1}$ Adjusted for all the covariates. 
alization of our findings. Women delivered at the maternity are more likely to be educated and of a higher socioeconomic status than the typical pregnant woman in the community. The institutional coverage of births is very low, and only a few pregnant women visit a health facility at some point of their pregnancy because of geographical, economic and cultural barriers in access to healthcare. ${ }^{32}$ Most deliveries in Angola remain in non-medical settings, women delivering at home with the help of traditional birth attenders. According to 2015-16 Multiple Indicator and Health Survey only $50 \%$ of births were attended by skilled personnel in Angola. ${ }^{32}$ The evaluation of the baseline household survey data from the Measurement, Learning \& Evaluation Project for the Nigerian Urban Reproductive Health Initiative, implemented in six major cities, showed that attitudes against domestic violence were significantly and positively associated with delivering in a health facility and also with a skilled attendant at birth. ${ }^{14}$ If a similar process of women empowerment operates in Angola, the frequency of violence in our study population might be additionally underestimated. We did not opt for a standardized questionnaire to measure violence. Nevertheless, the acts assessed and considered for physical, psychological and sexual violence, can be found in commonly used standardized scales for measurement of violence during pregnancy, as in the Abuse assessment screen. ${ }^{33}$ As a first approach to the problem, we decided to consider the questions on violence as part of a general questionnaire on perinatal health and did not collect information on such items as the frequency of violent acts, duration of violence and severity of episodes, and just concentrated on the pregnancy period. This decision limited the amount of information and might hamper comparability, but we think that allowed an essential baseline for future research namely considering the need to train personnel, raise awareness and guarantee the privacy and a safe environment for women who need it.

In our survey, besides the lack of social awareness, women may not have disclosed violence because of shame or fear of the consequences since they might perceive the hospital environment as a not private setting and other women who delivered in the same hospital ward were nearby.

Future research should include qualitative research in order to better understand the context of violent situations, perceptions and attitudes towards violence among these women.

Pregnancy is a period of life that may demand increased relationship commit- ment, increase economic dependency and healthcare needs, and thus the impact of some risk factors is likely to be more relevant during pregnancy ${ }^{34}$ especially in developing nations where the effects of resources scarcity may be particularly prominent. ${ }^{35}$ Antenatal care is often the only point of contact with health care services and provides a window of opportunity for identifying women who experience violence. It is necessary to incorporate violence as an element of preventive care in the health of the mother. A recent review of violence reduction interventions stated that the evidence for the effectiveness of advocacy and support interventions is growing, and that psychological interventions may be effective, but that more research is needed, especially since no trials of screening programs measured morbidity and mortality. ${ }^{36,37}$

As a conclusion, we found a high prevalence of violence during pregnancy as assessed in a relatively favored social context and that physical violence increased the risk of low birth weight. Antenatal care content should consider violence assessment as a major modifiable risk factor, and women are accompanied and advised. No specific guidelines for screening violence during health visits currently exist in Angola, but our data make such orientation an urgent need. The present findings might additionally contribute to design women and child health programs in the Angolan context that promote more comprehensive strategies leading to finally reach the targets set as the Millennium Development Goals, ${ }^{38}$ and contributing to the Sustainable Development Goals. ${ }^{39}$

\section{References}

1. Garcia-Moreno C, Jansen HA, Ellsberg $\mathrm{M}$, et al. Prevalence of intimate partner violence: findings from the WHO multi-country study on women's health and domestic violence. Lancet 2006;368:1260-9.

2. Maciel MNA, Blondel B, SaurelCubizolles MJ. Physical Violence During Pregnancy in France: Frequency and Impact on the Health of Expectant Mothers and New-Borns. Matern Child Health J 2019;23:1108-16.

3. Nesari M, Olson JK, Vandermeer B, et al. Does a maternal history of abuse before pregnancy affect pregnancy outcomes? A systematic review with metaanalysis. BMC Pregnancy Childbirth 2018;18:404.

4. Han A, Stewart DE. Maternal and fetal outcomes of intimate partner violence associated with pregnancy in the Latin American and Caribbean region. Int $\mathrm{J}$ Gynaecol 2014;124:6-11.

5. Shamu S, Abrahams N, Temmerman M, et al. A systematic review of African studies on intimate partner violence against pregnant women: prevalence and risk factors. PloS One 2011;6:e17591.

6. Alebel A, Kibret GD, Wagnew F, et al. Intimate partner violence and associated factors among pregnant women in Ethiopia: a systematic review and metaanalysis. Reprod Health 2018;15:196.

7. Taillieu TL, Brownridge DA. Violence against pregnant women: Prevalence, patterns, risk factors, theories, and directions for future research. Aggress Violent Behav 2010;15:14-35.

8. World Health Organization. Multicountry Study on Women's Health and Domestic Violence against Women. Initial results on prevalence, health outcomes and women's responses. Geneva: World Health Organization.2005.

9. Karamagi CA, Tumwine JK, Tylleskar $\mathrm{T}$, Heggenhougen K. Intimate partner violence against women in eastern Uganda: Implications for HIV prevention. BMC Public Health 2006;6:284.

10. McFarlane J, Campbell JC, Sharps P, Watson K. Abuse during pregnancy and femicide: urgent implications for women's health. Obstetrics Gynecol 2002;100:27-36.

11. Koenig LJ, Whitaker DJ, Royce RA, et al. Physical and sexual violence during pregnancy and after delivery: a prospective multistate study of women with or at risk for HIV infection. Am J Public Health 2006;96:1052-9.

12. Rodrigues $\mathrm{T}$, Rocha L, Barros $\mathrm{H}$. Physical abuse during pregnancy and preterm delivery. Am J Obstet Gynecol 2008;198:171.

13. Heindel JJ, Vandenberg LN. Developmental origins of health and disease: a paradigm for understanding disease cause and prevention. Curr Opin Pediatr 2015;27:248-53.

14. Corroon M, Speizer IS, Fotso JC, et al. The role of gender empowerment on reproductive health outcomes in urban Nigeria. Maternal Child Health J 2014; 18:307-15.

15. Shamu S, Zarowsky C, Roelens K, et al. High-frequency intimate partner violence during pregnancy, postnatal depression and suicidal tendencies in Harare, Zimbabwe. Gen Hospital Psychiatry 2016;38:109-14.

16. Dean AG, Sullivan K, Arner TG, et al. Epi Info 2000, a database and statistics program for public health professionals. 
Atlanta, Georgia, USA: Centers for Disease Control and Prevention; 2000.

17. Larsen PS, Kamper-Jorgensen M, Adamson A, et al. Pregnancy and birth cohort resources in europe: a large opportunity for aetiological child health research. Paediatr Perinat Epidemiol 2013;27:393-414.

18. Ellsberg M, Heise L, Pena R, et al. Researching domestic violence against women: methodological and ethical considerations. Stud Fam Plan 2001;32: 1-16.

19. McFarlane J, Parker B, Soeken K, Bullock L. Assessing for abuse during pregnancy. Severity and frequency of injuries and associated entry into prenatal care. JAMA 1992;267:3176-8.

20. Devries KM, Kishor S, Johnson H, et al. Intimate partner violence during pregnancy: analysis of prevalence data from 19 countries. Reprod Health Matters 2010;18:158-70.

21. National Population Commission [Nigeria] and ICF International. Gender in Nigeria: Data from the 2013 Nigeria Demographic and Health Survey (NDHS). Rockville, Maryland, USA: National Population Commission and ICF International 2014.

22. Uthman AO. Factors associated with attitudes towards intimate partner violence against women: a comparative analysis of 17 sub Saharan countries. BMC Int Health Hum Rights 2009;20: 14.

23. Abrahams N, Devries K, Watts C, et al. Worldwide prevalence of non-partner sexual violence: a systematic review. Lancet 2014;383:1648-54.

24. Ntaganira J, Muula AS, Masaisa F, et al. Intimate Partner Violence among pregnant women in Rwanda. BMC Womens
Health 2008;8:17.

25. Urquia ML, O'Campo PJ, Heaman MI, et al Experiences of violence before and during pregnancy and adverse pregnancy outcomes: an analysis of the Canadian Maternity Experiences Survey. BMC Pregnancy Childbirth 2011;11:42

26. Valladares E, Pena R, Ellsberg M, et al. Neuroendocrine response to violence during pregnancy-impact on duration of pregnancy and fetal growth. Acta Obstet Gynecol Scandin 2009;88:81823.

27. Kaye DK. Gender inequality and domestic violence: implications for human immunodeficiency virus (HIV) prevention. Afr Health Sci 2004;4:6770.

28. Heise LL, Raikes A, Watts CH, Zwi AB. Violence against women: a neglected public health issue in less developed countries. Soc Sci Med 1994;39:116579 .

29. Meuleners LB, Lee AH, Janssen PA, Fraser ML. Maternal and foetal outcomes among pregnant women hospitalised due to interpersonal violence: A population based study in Western Australia, 2002-2008. BMC Pregn Childbirth 2011;11.

30. Donovan BM, Spracklen CN, Schweizer ML, et al. Intimate partner violence during pregnancy and the risk for adverse infant outcomes: a systematic review and meta-analysis. BJOG 2016 Mar 9.

31. Campbell J, Torres S, Ryan J, et al. Physical and nonphysical partner abuse and other risk factors for low birth weight among full term and preterm babies: a multiethnic case-control study. Am J Epidemiol 1999;150:714-26.
32. Instituto Nacional de Estatística (INE), Ministério da Saúde (MINSA), Ministério da Planeamento e do Desenvolvimento Territorial (MPDT) and ICF. Key Findings of the 2015-16 Multiple Indicator and Health Survey Angola. Luanda, Angola. Rockville, Maryland, U.S.A: INE, MINSA, MPDT and ICF2017.

33. McFarlane J, Greenberg L, Weltge AMW. Identification of abuse in emergency departments: effectiveness of a two-question screening tool. J Emerg Nurs 1995;21:391-4.

34. World Health Organization. Intimate partner violence during pregnancy WHO/RHR/11.35. Geneva: WHO Department of Reproductive Health and Research 2011.

35. Choi SY, Ting KF. Wife beating in South Africa: an imbalance theory of resources and power. J Interpersonal Violence 2008;23:834-52.

36. Van Parys AS, Verhamme A, Temmerman M, Verstraelen H. Intimate partner violence and pregnancy: a systematic review of interventions. PloS One 2014;9:e85084.

37. Hassan M, Kashanian M, Hassan M, Roohi MHY. Maternal outcomes of Intimate Partner Violence during pregnancy: study in Iran. Public Health 2014;128:410-5.

38. Victora CG, Requejo JH, Barros AJ, et al. Countdown to 2015: a decade of tracking progress for maternal, newborn, and child survival. Lancet 2015 Oct 15.

39. Mancuso L, Johnson P, Hart L, Austin K. Addressing Maternal and Newborn Health: A Leadership Perspective. World Health Popul 2015;16:7-15. 